\title{
FORMULATION AND EVALUATION OF GASTRO RETENTIVE DRUG DELIVERY SYSTEM OF ZANAMIVIR USING DIFFERENT POLYMERS
}

\author{
V. Vijaya Kumar ${ }^{1 *}$, B. Deekshi Gladiola, C. Madhusudhana Chetty ${ }^{1}$, R. E.Ugandar ${ }^{1}$
}

Department of Pharmaceutics, Santhiram College of Pharmacy, Nandyal.

Article Info: Received 10 July 2019; Accepted 16 August. 2019

DOI: https://doi.org/10.32553/jbpr.v8i4.641

Address for Correspondence: V. Vijaya Kumar, Associate Professor, Department of Pharmaceutics, Santhiram College of Pharmacy, Nandyal, Kurnool Dist, Andhra Pradesh.

Conflict of interest statement: No conflict of interest

\section{ABSTRACT:}

The objective of the present study is to develop gastro retentive drug delivery system of Zanamivir .Floating tablets of Zanamivir were developed with a gas generating agent $\mathrm{NaHCO}_{3}$ and in $\mathrm{combination}$ of different hydrophobic and hydrophilic polymers like xanthan gum, guar gum, HPMC and methyl cellulose .In the present work attempts have been made to prepare six formulations of Zanamivir in different ratios of drug and polymer to get a desired release profile by direct compression method.All the prepared tablets were evaluated in terms of pre compression and post compression parameters. FTIR studies revealed the absence of drug polymer interactions. Among all the formulations F5 Showed $97.4 \%$ of in vitro drug release for 10 hours and hence formulation F5 is selected as an optimized formulation. The optimized formulation F5 was found to follow Higuchi release kinetics and zero order. Further formulation F5 was subjected to accelerated stability studies for 3 months. It showed that the optimized formulation was intact without any interactions. Finally the optimized formulation F5 complying with all properties of floating tablets was found to be satisfactory

Keywords: Zanamivir, floating tablet, natural gums, sodium bicarbonate, gastro retentive drug delivery systems

\section{INTRODUCTION}

Oral drug administration is the most convenient mode of delivery when compared to other routes .Due to its ease of administration, it has widely accepted patient compliance and to maintain the drug concentration within the therapeutic range, these dosage forms are to be taken several times in a day .This resulted in a fluctuated drug level and consequently undesirable toxicity and poor efficiency. ${ }^{1}$ To overcome these demerits an unique oral controlled dosage forms known as gastro retentive dosage forms were developed These dosage forms possess gastro retentive properties which can retain in the stomach for longer period of time and hence significantly prolong GRT of drugs which improves bioavailability, reduces wastage and improves the solubility of drug in the GIT. ${ }^{2}$ Several approaches were attempted by researchers for enhancing gastric retention such as floating systems, swelling systems, bio adhesive systems and high density systems .Floating drug delivery systems have a bulk density lower than gastric fluid and thus remain buoyant in the stomach for a prolonged period of time. This results in an increase gastric retention time and a better control of fluctuations in plasma drug concentration. ${ }^{3}$.Zanamivir is an acetyl guanido neuraminic acid, a structural homolog of sialic acid. It is a white crystalline powder and was found to be highly soluble in water. ${ }^{4}$ Zanamivir acts as an antiviral agent and neuraminidase inhibitor indicated for the treatment of influenza $A$ and Influenza $B$. The elimination half life of zanamivir is about 2.5 to 5.1 hours. $^{5}$

\section{MATERIALS AND METHODS:}

\section{Materials:}

Zanamivir was obtained from Chandra labs, Hyderabad. Xanthan gum and guar gum were purchased from Mylchem, Mumbai, HPMC and PVP are obtained from Sysco Research labs Pvt, Ltd. Mumbai. NaHCO3, Microcrystalline cellulose ,Magnesium stearate were purchased from SD Fine Chemicals Ltd, Mumbai. 


\section{Methods:}

\section{FTIR studies:}

The physical compatibility of drug and polymer is an important step in selecting the suitable excipients for a stable and strong formulation. It is necessary to confirm that there exists no interaction between the drug and polymer as it can affect the shelf life of the product .Compatibility studies were performed using FTIR spectrophotometer. FTIR spectra of the drug and drug along with the excipients was recorded in the range of $4000-400 \mathrm{~cm}-1$ using potassium bromide(pellet method) and the obtained IR spectra was compared to that of reference spectra of Zanamivir ${ }^{6}$.

\section{FORMULATION DEVELOPMENT:}

Preparation of floating tablets of Zanamivir:

The gastro retentive floating tablets were prepared using HPMC, guar gum, xanthan gum, micro crystalline cellulose as diluent and $\mathrm{NaHCO}_{3}$ as gas generating agent, magnesium stearate as a lubricant, talc as a glidant. The drug and the excipients were individually passed through sieve60 before preparation of dosage form. All the ingredients were mixed thoroughly by triturating up to $15 \mathrm{~min}$ to ensure uniform mixing. Tablets (350mg) were prepared in total of six formulations according to the formulation table shown in Table 1.

Table 1: Composition of different formulations

\begin{tabular}{|l|l|l|l|l|l|l|}
\hline Ingredients (mg) & F1 & F2 & F3 & F4 & F5 & F6 \\
\hline Zanamivir & 75 & 75 & 75 & 75 & 75 & 75 \\
\hline HPMC & 105 & 122.5 & 140 & -- & -- & -- \\
\hline Xanthum gum & -- & -- & & 105 & -- & -- \\
\hline Guar gum & -- & -- & & -- & 105 & -- \\
\hline Ethyl cellulose & -- & -- & & -- & -- & 105 \\
\hline PVP & 17.5 & 17.5 & 17.5 & 17.5 & 17.5 & 17.5 \\
\hline Sodium bicarbonate & 52.5 & 52.5 & 52.5 & 52.5 & 52.5 & 52.5 \\
\hline MCC & 96.5 & 79 & 61.5 & 96.5 & 96.5 & 96.5 \\
\hline Magnesium stearate & 3.5 & 3.5 & 3.5 & 3.5 & 3.5 & 3.5 \\
\hline Total weight & $350 \mathrm{mg}$ & $350 \mathrm{mg}$ & $350 \mathrm{mg}$ & $350 \mathrm{mg}$ & $350 \mathrm{mg}$ & $350 \mathrm{mg}$ \\
\hline
\end{tabular}

The prepared tablets were then evaluated for the various pre compression and post compression parameters.

\section{EVALUATION OF TABLET PROPERTIES:}

\section{Pre-compression parameters:}

\section{Bulk density and Tapped density:}

A known amount of sample was taken in a10 ml graduated cylinder separately and the volume was noted down. The graduated measuring cylinder was tapped 100 times using USP bulk density apparatus. The bulk density and tapped density were calculated by following formula: ${ }^{7}$

Bulk density $=$ mass of powder $\div$ volume of powder

Tapped density =mass of powder $\div$ volume of powder after tapping

\section{Carr's index:}

It indicates the ease with which a material can be induced to flow and expressed in \%.

\section{Hausners ratio:}

The flow properties can be measured by Hausner's ratio by comparing tapped density with that of bulk density.

\section{Angle of repose:}

It can be defined as the maximum angle possible between the surface of pile of powder to the horizontal plane. The angle of repose for the granules of each formulation can be determined by funnel method. ${ }^{8}$

\section{Post compression parameters:}

\section{Weight variation:}

Twenty tablets were selected at random and the average weight of the tablet was determined using electronic balance. The weight of individual tablets was compared to that of average weight ${ }^{9}$ 
$\%$ weight variation= average weight-individual weight $\div$ average weight $\times 100$

\section{Hardness test:}

Hardness of the prepared tablets was determined using Monsanto hardness tester. It is measured in $\mathrm{kg} / \mathrm{cm} 2$ and provides information about withstand ability during handling. ${ }^{10}$

\section{Friability test:}

Twenty previously weighed tablets were taken in the friability apparatus, which was given 100 revolutions and the tablets were re weighed. The percentage friability was calculated by the formula: 11

$\% \quad$ Friability=initial weight-final weight $\div$ initial weight $\times 100$

\section{Drug content:}

Twenty tablets of each formulation were weighed and powdered. The quantity of powder equivalent to $100 \mathrm{mg}$ of drug was transferred into a100 ml volumetric flask and volume is made up to $100 \mathrm{ml}$ using $0.1 \mathrm{~N} \mathrm{HCL}$. Further $1 \mathrm{ml}$ of above solution is diluted to $100 \mathrm{ml}$ with $0.1 \mathrm{~N} \mathrm{HCL}$ and absorbance of the resulting solution was observed at $216 \mathrm{~nm}$ using UV spectrophotometer. ${ }^{12}$

Drug content=concentration $\times$ dilution factor

$\%$ Drug content $=$ Drug Content $(\mathrm{mg}) \div$ label claim (mg) $\times 100$

\section{In-vitro buoyancy studies:}

The in vitro buoyancy was determined by floating lag time and total floating time. The tablets were placed in a $100 \mathrm{ml}$ beaker containing $0.1 \mathrm{~N} \mathrm{HCL}$. The time required for the tablet to raise the surface and float was determined as floating lag time and the duration of time the tablet consistently floats on the dissolution medium was determined as total floating time. Buoyancy character of floating tablets was shown in Figure 3. ${ }^{13}$

\section{Swelling index:}

The swelling index of tablets was determined by placing the tablets in the basket of dissolution apparatus using dissolution medium $0.1 \mathrm{~N} \mathrm{HCL}$ at $37 \pm 0.5^{\circ} \mathrm{C}$. The experiment was performed in triplicate for each time point .Swelling index was calculated by using the following formula. ${ }^{14}$
Swelling index $=$ Wet weight of tablet - Dry weight of tablet $\div$ Dry weight

\section{In-vitro dissolution studies:}

$900 \mathrm{ml}$ of $0.1 \mathrm{~N} \mathrm{HCL}$ was placed in the vessel and the USP apparatus II (paddle method) was assembled. The medium was allowed to equilibrate to temperature of $37 \pm 0.5 \mathrm{c}$. Tablet was placed in the vessel, and the vessel was covered . The apparatus was operated for 10 hours at $50 \mathrm{rpm}$. At definite intervals, $5 \mathrm{ml}$ of the fresh buffer was replaced. Suitable dilutions were done with the dissolution fluid and the sample was analyzed by UV spectro photometer at $216 \mathrm{~nm}$, using $0.1 \mathrm{~N} \mathrm{HCl}$ solution as a blank. ${ }^{15}$

\section{Release kinetics:}

The mechanism of drug release from the floating tablets was determined by fitting the data obtained from in vitro dissolution studies to various models like higuchi model, Korsemeyer- Peppas model, first order, and zero order. ${ }^{16}$

\section{Stability studies:}

Stability studies were carried out according to $\mathrm{ICH}$ guidelines.Theoptimized formulation of Zanamivir were packed in aluminium pouch and subjected to accelerated stability at $40 \pm 2^{\circ} \mathrm{C} / 75 \% \mathrm{RH}$ for a period of three months. Samples from each formulation which are kept for examination were withdrawn at definite time intervals and evaluated for their drug content, in vitro buoyancy studies and for in vitro drug release. ${ }^{17}$

\section{RESULTS AND DISCUSSION:}

FTIR spectra of the drug and drug along with the excipients was recorded in the range of 4000_400 $\mathrm{cm}$ - using potassium bromide(pellet method) and the obtained IR spectra was compared to that of reference spectra of Zanamivir.

\section{EVALUATION OF ZANAMIVIR FLOATING TABLETS:}

\section{Pre compression parameters:}

Results of the pre compression parameters performed on the blend for the formulations(F1F6) are shown in Table 2. The bulk density for all the formulations varied from $0.45 \mathrm{~g} / \mathrm{ml} \pm 0.72 \mathrm{~g} / \mathrm{ml}$. Tapped density varied between $0.48 \mathrm{~g} / \mathrm{ml} \pm 0.87 \mathrm{~g}$ $/ \mathrm{ml}$. Carr's value ranged between $12.23 \pm 0.6 \%$ to $19.71 \pm 0.71 \%$. Hausner's ratio was found between $1.11 \pm 0.04 \%$ and $1.25 \pm 0.04 \%$.based on the results 
V. Vijaya Kumar et al, Journal of Biomedical and Pharmaceutical Research

obtained through angle of repose, compressibility index and Hausner's ratio it can be concluded that all the six formulations showed good flow properties.

Table 2: Pre-compression parameters for formulations F1-F6

\begin{tabular}{|l|l|l|l|l|l|}
\hline $\begin{array}{l}\text { Formulation } \\
\text { code }\end{array}$ & $\begin{array}{l}\text { Bulk density } \\
\text { (gm/ml) }\end{array}$ & $\begin{array}{l}\text { Tapped density } \\
\text { (gm/ml) }\end{array}$ & $\begin{array}{l}\text { Compressibility } \\
\text { index (\%) }\end{array}$ & Hausners ratio & $\begin{array}{l}\text { Angle of } \\
\text { repose }\end{array}$ \\
\hline F1 & $0.721 \pm 0.045$ & $0.87 \pm 0.01$ & $17.126 \pm 0.6$ & $1.206 \pm 0.06$ & $26.62 \pm 0.21$ \\
\hline F2 & $0.710 \pm 0.043$ & $0.873 \pm 0.04$ & $19.714 \pm 0.7$ & $1.251 \pm 0.04$ & $27.46 \pm 0.11$ \\
\hline F3 & $0.41 \pm 0.045$ & $0.483 \pm 0.5$ & $15.113 \pm 0.8$ & $1.178 \pm 0.08$ & $28.32 \pm 0.31$ \\
\hline F4 & $0.45 \pm 0.045$ & $0.52 \pm 0.09$ & $15.60 \pm 0.2$ & $1.15 \pm 0.02$ & $28.06 \pm 0.31$ \\
\hline F5 & $0.45 \pm 0.045$ & $0.50 \pm 0.07$ & $12.23 \pm 0.6$ & $1.11 \pm 0.04$ & $27.58 \pm 0.15$ \\
\hline F6 & $0.44 \pm 0.044$ & $0.50 \pm 0.09$ & $12.58 \pm 0.8$ & $1.13 \pm 0.08$ & $28.44 \pm 0.11$ \\
\hline
\end{tabular}

\section{Post compression parameters:}

The formulated tablets of Zanamivir were subjected to various post compression parameters such as average weight, hardness, and friability, determination of drug content, floating time, and buoyancy time. The results obtained for all these parameters are represented in Table 3 and results obtained for swelling index are represented in Table 4

Table 3: Post compression evaluation parameters of Zanamivir floating Tablets

\begin{tabular}{|l|l|l|l|l|l|l|}
\hline $\begin{array}{l}\text { Formulation } \\
\text { No. }\end{array}$ & $\begin{array}{l}\text { Avg. Weight } \\
(\text { Mean } \pm \text { S.D) } \\
(\mathrm{n}=20)\end{array}$ & $\begin{array}{l}\text { Hardness } \\
\left(\mathrm{kg} / \mathrm{cm}^{2}\right) \\
(\mathrm{n}=3)\end{array}$ & $\begin{array}{l}\text { Friability } \\
(\text { Mean } \pm \text { S.D) } \\
(\mathrm{n}=20)\end{array}$ & $\begin{array}{l}\text { \% Drug } \\
\text { content } \\
(\mathrm{mg})\end{array}$ & $\begin{array}{l}\text { Buoyancy } \\
\text { Lag time } \\
(\mathrm{min})\end{array}$ & $\begin{array}{l}\text { Total floating } \\
\text { Time(hrs })\end{array}$ \\
\hline F1 & $353 \pm 0.6$ & $7.2 \pm 0.4$ & 0.546 & $98 \pm 0.7$ & 26 & 5 \\
\hline F2 & $350 \pm 0.9$ & $7.5 \pm 0.4$ & 0.612 & $99 \pm 0.5$ & 18 & 6 \\
\hline F3 & $347 \pm 0.3$ & $7.4 \pm 0.6$ & 0.527 & $98 \pm 0.6$ & 20 & 10 \\
\hline F4 & $351 \pm 0.4$ & $7.6 \pm 0.1$ & 0.511 & $99 \pm 0.6$ & 3 & 8 \\
\hline F5 & $346 \pm 0.8$ & $7.6 \pm 0.6$ & 0.525 & $99 \pm 0.6$ & 6 & 8 \\
\hline
\end{tabular}

Table 4: Swelling index studies of Zanamivir floating Tablets

\begin{tabular}{|c|c|c|c|c|c|c|}
\hline \multirow[b]{2}{*}{ Time(hr) } & \multicolumn{5}{|c|}{ Swelling index ratio } & \multirow[b]{2}{*}{ F6 } \\
\hline & F1 & F2 & F3 & F4 & F5 & \\
\hline 0 & 0 & 0 & 0 & 0 & 0 & 0 \\
\hline 2 & 32 & 35 & 42 & 46 & 50 & 55 \\
\hline 4 & 46 & 48 & 50 & 51 & 58 & 60 \\
\hline 6 & 52 & 55 & 58 & 65 & 67 & 72 \\
\hline
\end{tabular}




\section{In-vitro dissolution:}

An Invitro dissolution study of prepared Zanamivir floating tablets was carried up to $10 \mathrm{hrs}$. The samples are withdrawn at regular intervals have been evaluated using UV Visible spectrophotometer. Results of drug release of all the formulations were shown in Table No: 5 and release kinetics were shown in Table 6. Comparative in vitro drug release plot of all the formulations were shown in Figure 1.Formualtion F5 was found to be an optimized formulation shows sustained drug release for $10 \mathrm{hrs}$ with a maximum of $96.3 \%$ of cumulative drug release at the end of $10^{\text {th }}$ hour.

Table 5: Dissolution Data of Zanamivir Floating Tablets

\begin{tabular}{|l|l|l|l|l|l|l|}
\hline TIME (hr) & F1 & F2 & F3 & F4 & F5 & F6 \\
\hline 1 & 18.8 & 14.3 & 11.3 & 16.5 & 12.4 & 9.2 \\
\hline 2 & 39.9 & 22.2 & 21.4 & 29.8 & 30.8 & 19.3 \\
\hline 3 & 52.3 & 37.6 & 32.8 & 41.9 & 42.3 & 26.9 \\
\hline 4 & 76.9 & 46.8 & 46.1 & 50.2 & 49.4 & 38.2 \\
\hline 5 & 92.8 & 76.8 & 58.4 & 61.1 & 60.3 & 46.8 \\
\hline 6 & -- & 96.3 & 69.5 & 72.7 & 76.4 & 58.3 \\
\hline 8 & -- & -- & 79.9 & 96.3 & 90.2 & 71.4 \\
\hline 10 & -- & -- & 90.4 & -- & 97.4 & 84.9 \\
\hline
\end{tabular}

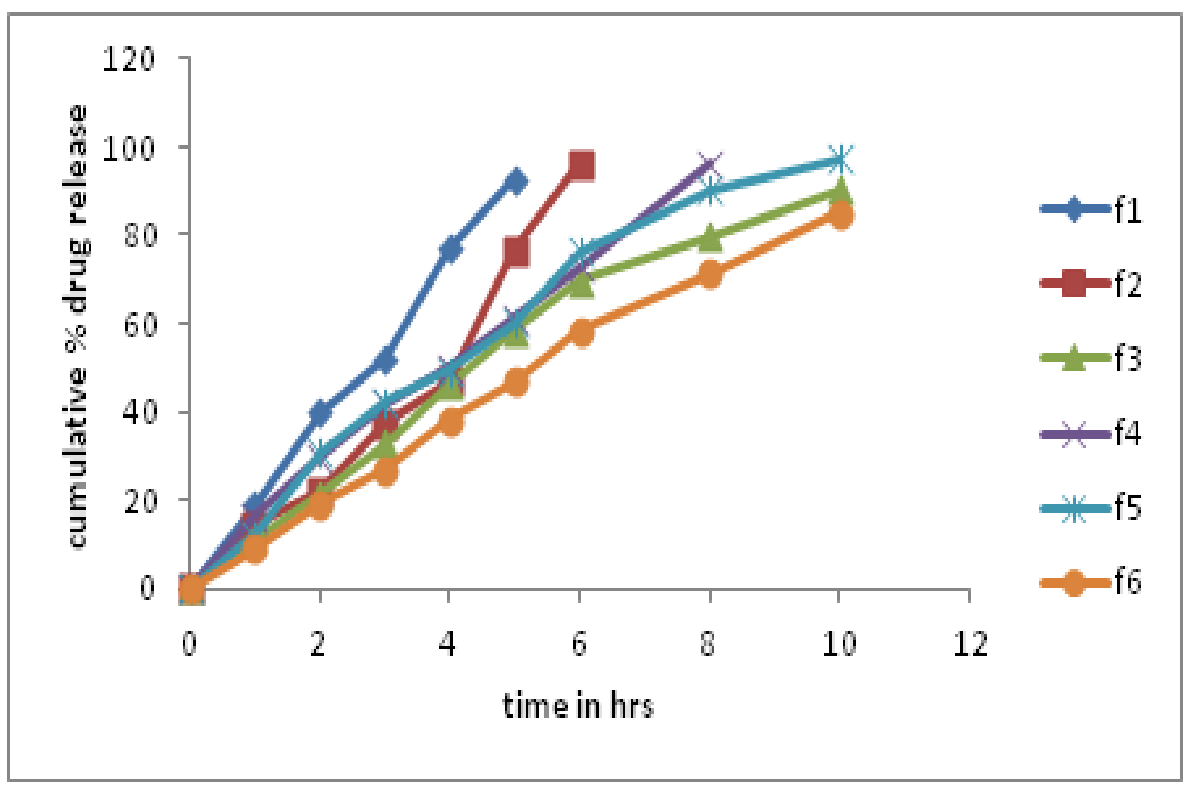

Figure 3: Comparitive Invitro drug release of Formulations F1-F6

Table 6: In-vitro drug release kinetics of optimized formulation F5

\begin{tabular}{|l|l|l|l|l|}
\hline & $\begin{array}{l}\text { ZERO } \\
\text { ORDER }\end{array}$ & $\begin{array}{l}\text { FIRST } \\
\text { ORDER }\end{array}$ & $\begin{array}{l}\text { HIGUCHI } \\
\text { ORDER }\end{array}$ & $\begin{array}{l}\text { PEPPAS } \\
\text { ORDER }\end{array}$ \\
\hline Slope & 10.04806202 & -0.15129636 & 33.72313307 & 1.456766715 \\
\hline Intercept & 7.480620155 & 2.169599642 & -12.0120347 & 0.730487873 \\
\hline Correlation & 0.982305508 & -0.96099032 & 0.977202195 & 0.851331954 \\
\hline $\mathrm{R}^{2}$ & 0.964924111 & 0.923502408 & 0.95492413 & 0.724766096 \\
\hline
\end{tabular}




\section{Stability studies:}

During and at the end of the accelerated stability, the tested tablets showed non significantly different drug content from that obtained at the beginning of the study. They also showed satisfactory hardness and buoyancy properties during and the end of the accelerated study period. The results of stability studies are shown in table -7.

Table 7: Stability data of optimised formulation F5

\begin{tabular}{|l|l|l|l|l|l|l|}
\hline \multirow{2}{*}{ Sr. No } & Time points (hr) & \multirow{2}{*}{ Initial } & \multicolumn{4}{|c|}{ Cumulative \% Drug Release (mean \pm SD) $(\mathrm{n}=3)$} \\
\cline { 4 - 7 } & & & $25^{\circ} \mathrm{C} / 60 \% \mathrm{RH}$ & \multicolumn{2}{l|}{$40^{\circ} \mathrm{C} / 75 \% \mathrm{RH}$} \\
\cline { 4 - 7 } & & & 1st Month & 3rd Month & 1stMonth & 3rdMonth \\
\hline 1 & 1 & 12.4 & 12.2 & 11.7 & 11.2 & 10.7 \\
\hline 2 & 2 & 30.8 & 30.4 & 30.1 & 29.4 & 29.1 \\
\hline 3 & 3 & 42.3 & 42.1 & 41.8 & 39.6 & 39.2 \\
\hline 4 & 4 & 49.4 & 49.0 & 48.6 & 47.8 & 47.4 \\
\hline 5 & 5 & 60.3 & 58.3 & 59.4 & 59.1 & 58.6 \\
\hline 6 & 6 & 76.4 & 76.1 & 75.5 & 75.1 & 74.9 \\
\hline 7 & 8 & 90.2 & 89.8 & 89.2 & 88.7 & 88.1 \\
\hline 8 & 10 & 97.4 & 97.1 & 96.5 & 96.1 & 95.8 \\
\hline 9 & Assay & 99.5 & 99.2 & 99.1 & 98.7 & 98.9 \\
\hline
\end{tabular}

\section{CONCLUSION:}

In this study an attempt has been made by formulating floating tablets of Zanamivir by addition of various combinations of HPMC, xanthan gum, guar gum, methyl cellulose, $\mathrm{NaHCO} 3$ and their effectiveness on floating tablets were studied. Total six formulations floating tablets of Zanamivir were prepared by direct compression and were subjected to various evaluation tests. FTIR spectra of physical mixture of Zanamivir and excipients confirmed the absence of the interactions between the drug and the excipients. Among all the six formulations F5 was found to be good with desired dissolution profile. The tablets showed sustained and zero order drug release and follow higuchi model with mechanism of non fickian diffusion. The accelerated studies revealed that the tablets can be stored at room temperature.

\section{REFERENCES:}

1. Amin AF, Dave BS, Patel MM. Gastro retentive drug delivery system of ranitidine hydrochloride: formulation and in vitro evaluation. AAPS Pharm Sci .Tech 2004; Vol: 26.

2. P.G.Yeole, Floating Drug Delivery System: Need and Development, Ind. J. Pharm. Sci., (2005): 67(3); 265-272

3. Dave BS, Amin AF, Patel MM. Gastro retentive Drug Delivery System of Ranitidine Hydrochloride:
Formulation and In Vitro Evaluation. AAPS Pharm. Sci. Tech 2004; Vol 5

4. Anilkumar J. Shinde, Manojkumar S. Patel and Harinath N. Formulation and in vitro evaluation of sustained release floating tablet of Cephalexin using hydrophilic polymers.Int. J. Pharma and Pharmaceutical Sci- 2010, Vol 2.

5. Pramod Patel Formulation and In VitroEvaluation of Floating Matrix Tablets of Ofloxacin .Asian J. Res. Pharm. Sci. 2011; Vol. 1: Issue 1, Pg 17-22.

6. S. B. Bhise and N. H. Aloorkar.Formulation and in vitro Evaluation of Floating Capsules of Theophylline. Indian. J. Pharm Sci. 2008 Mar-Apr; 70(2): 224-227.

7. Srivastava AK, Wadhwa S, Ridhurkar D, Mishra B. Oral sustained delivery of atenolol from floating matrix tablets-formulation and in vitro evaluation. Drug Dev. Ind. Pharm 2005; 31:367-74

8. Bomma R, Swamy Naidu RA, Yamsani MR, Veerabrahma K. Development and evaluation of gastro retentive norfloxacin tablets. Act. Pharma 2009; Vol: 59: pg: 211-21.

9. Li S, Lin S, Daggy BP, Mirchandani, HL, Chien, TW. Effect of formulation variables on the floating properties of gastric floating drug delivery system. Drug Dev. Ind. Pharm 2002; Vol-28: pg: 783-93.

10. Chander Shekar .B, Shireesh Kiran .R, and Nagendra Babu .B Preparation and evaluation of gastro retentive floating tablets of Ketoconazole. Int.j. Pharma Res and develop. November - 2010 / Vol: 2 / Issue - 9 pg, 174-184 


\section{Vijaya Kumar et al, Journal of Biomedical and Pharmaceutical Research}

11. J. SahooP, N. Murthy ${ }_{2}$ S. Biswal, S. K. SahooandA. K. Mahapatra. Comparative Study of Propranolol hydrochloride Release from Matrix Tablets with Kollidon $^{\circledR}$ SR or Hydroxy Propyl Methyl CelluloseAAPS Pharmscitech. 2008 June; Vol-9(2): pg: 577-582.

12. Rahman Z, Mushir A, Khar RK. Design and evaluation of Bilayer floating tablets of captopril. Act. Pharm 2006; Vol: 56: pg: 49-57.

13. ST Prajapati, LD Patel and DM Patel. Studies on Formulation and In Vitro Evaluation of Floating Matrix Tablets of Domperidone.Indian. J Pharm Sci. 2009 Jan-Feb; Vol-71(1): pg: 19-23.
14. Shweta Aurora, Floating Drug Delivery: A Review, AAPS Pharmscitech. (2005): 47(11); P.268-272

15. Pramod Patel Formulation and In VitroEvaluation of Floating Matrix Tablets of Ofloxacin .Asian J. Res. Pharm. Sci. 2011; Vol. 1: Issue 1, Pg 17-22

16. Narendra C, Srinath MS, Babu G. Optimization of Bilayer Floating Tablet Containing Nevirapine as a Model Drug for Gastric Retention. AAPS Pharm Sci Tech 2006; 7.

17. Tarique khan, Sayyed nazim, Siraj sheikh and Afsar sheikh. Design and In vitro evaluation of floating Diltiazem hydrochloride tablets based on gas formation. Int. J. Pharma and Bio Sci.2010, 3(6), pg: 1263-1267 